\title{
Two pericentric inversions of human chromosome 11
}

\author{
K. SIMOLA, P. KARLI, AND A. DE LA CHAPELLE \\ From the Folkhälsan Institute of Genetics, Helsinki, Finland; and the Department of Neurology, Unicersity \\ of Helsinki, Finland
}

SUMMARY A pericentric inv(11) (p15q23) detectable by G-, Q-, and R-banding and occurring in 1 member of each of 3 generations of a family is described. In another family studied by several banding methods in search of chromosomal markers, a pericentric inv(11) (p11q11) was found. It was detectable only by C-banding, the darkly staining band being located on the short-arm side of the centromere. The reasons for defining this aberration as an inversion rather than a location variant are outlined. This inversion occurred in 9 members of 3 generations of a large family.

There was no clear-cut evidence of any clinical consequences of these inversions either in heterozygotes or their offspring.

With the chromosome banding methods now available it has been established that pericentric inversions are not infrequent in the human chromosome complement. The clinical significance of these heritable marker chromosomes is not yet clear, but the available evidence suggests that the inversion itself does not cause clinical abnormalities (de la Chapelle et al., 1974). Recent findings reviewed by Moorhead (1976) indicate that the proportion of clinically abnormal offspring resulting from duplication-deficiency after crossing over within the inverted segment is small. Likewise, infertility in inversion carriers has not generally been noted. It may be, therefore, that some or most pericentric inversions cause little clinical harm.

The object of this paper is to describe two previously unrecorded pericentric inversions in chromosome 11 and their segregation.

\section{Methods}

Chromosome preparations were obtained from lymphocyte cultures with standard methods. Conventional staining of the chromosomes; G-banding (Seabright, 1971); C-banding (Arrighi and Hsu, 1971); Q-banding (Caspersson et al., 1970); and Rbanding (Dutrillaux and Lejeune, 1971) techniques were used.

\section{Results}

INV(11) (P15Q23)

The abnormal chromosome No. 11 was almost metacentric. In G-banded cells (Fig. 1) the terminal Received for publication 8 October 1976 lightly staining part of the short arm appeared longer than normal while the terminal part of the long arm was correspondingly shorter. Though band q24 is seldom visible in G-banded cells, a few cells showed it located towards the end of the short arm in the abnormal chromosome. These findings are compatible with a pericentric inversion comprising the greater part of both arms, with breakpoints at p15 and q23. Q- and R-banding were compatible with this interpretation while $\mathrm{C}$-banding was uninformative.

The proposita was studied cytogenetically after having had a normal boy followed by 3 spontaneous first trimester abortions (Fig. 2). She had inherited the inv(11) chromosome from her father, and had also passed it to her son. All 3 inversion heterozygotes were healthy and had no apparent anomalies. After the investigation the proposita gave birth to a healthy boy, who had a normal karyotype on pre- and postnatal investigations. Unfortunately all other relatives refused to co-operate so the further segregation of inv(11) in this large family could not be determined.

INV(11) (P11Q11)

This inversion was only detectable in C-banded cells. The position of the centromere was not measurably altered and G-, Q-, and R-banding showed nothing abnormal. In C-banded cells, the two No. 9 chromosomes could be identified on account of their large C-bands. In the individuals heterozygous for the inversion in No. 11, a third C-group chromosome could be consistently identified because its darkly staining C-band was on the short-arm side of the 


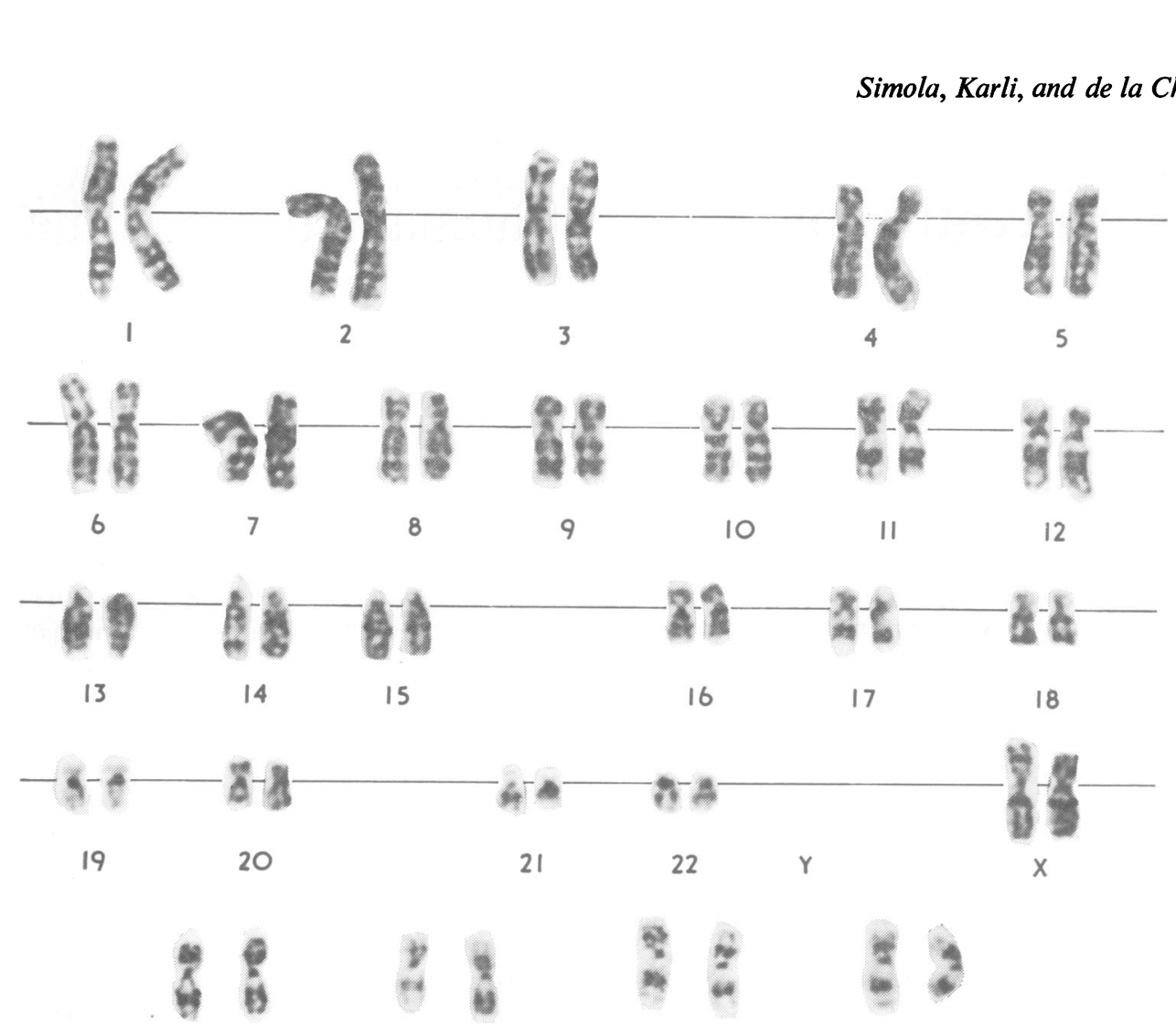

Fig. 1 G-banded karyotype of the proposita with inv(11) (p15q23). The bottom line shows the No. 11 chromosomes from 4 other metaphases. The right-hand homologue carries the inversion.

centromere while in all the others it was at the centromere itself (Fig. 3). The abnormal chromosome was a No. 11 as shown by cells successively stained by Q- and C-banding (Fig. 4).

This inversion was found during an investigation of chromosomal markers in a family in which the autosomal dominant gene for myotonic dystrophy was segregating. The proposita (Fig. 5) did not have the inv(11) chromosome, but was heterozygous for the common inversion of chromosome $9, \operatorname{inv}(9)$

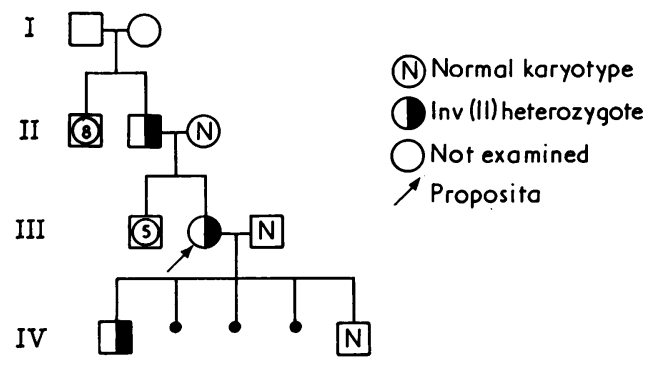

Fig. 2 Pedigree of the inv(11) (p15q23) family. (p1q13), which segregated independently of the inv(11). It should be noted that the mother of the proposita had the inv(11) without being related to the other carriers. Genealogical studies going back 5 and partly 6 generations failed to indicate a commop ancestor from whom both she and her husband's brother might have inherited the marker. However, a connection might well still exist, since both families originated from the same isolated parish.

Four persons heterozygous for inv(11) but withouf myotonic dystrophy were all healthy, whereas thes anomalies displayed by the five inv(11) heterozygotes. with myotonic dystrophy, such as high arched palate, spina bifida, pes equinovarus, and mentaP retardation, could all be attributed to the diseases (Pruzanski, 1966), and their dystrophic relatives with normal karyotypes also had similar anomalies? No spontaneous abortions or perinatal deaths were recorded in the family.

\section{Discussion}

$\operatorname{Inv}(11)(\mathrm{p} 15 \mathrm{q} 23)$ is the most likely interpretation of the chromosomal abnormality seen in the firstా 


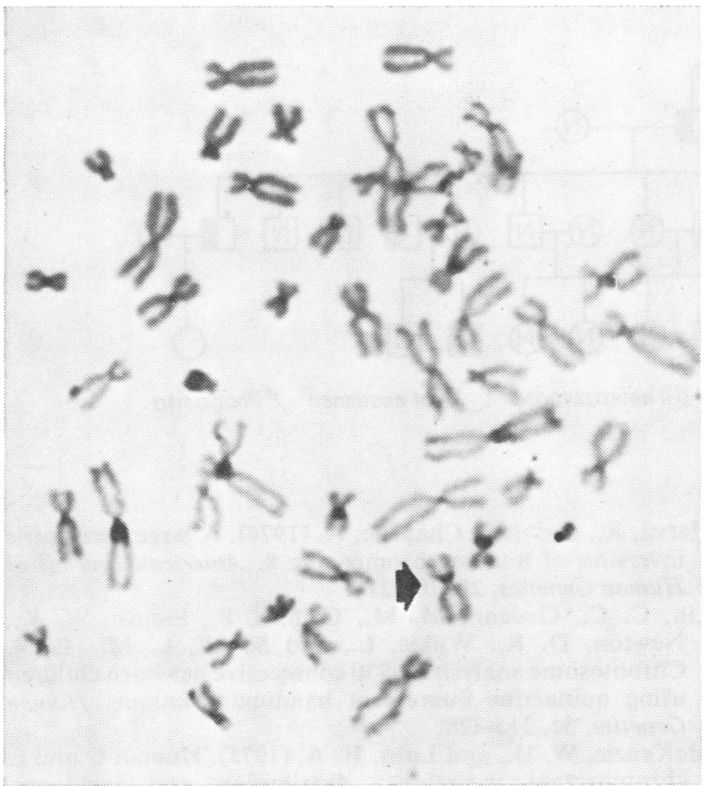

Fig. 3 C-banded metaphase showing inv(11) (p11q11) (arrow).

family. Neither a duplication-deficiency recombinant chromosome, nor a derivative of more complex chromosomal rearrangements appears likely. Hence we regard this inversion as established. By contrast, it may be a matter of definition whether the inv(11) (p11q11) is an inversion or merely a variant since it is detectable by one banding technique only (Cbanding).

A comparable situation pertains to the brightly fluorescent Q-band variant near the centromere in chromosome 3. Soudek et al. (1974) described the marker chromosome as an inv(3) (p13q12) when the brightest fluorescence was on the short-arm side of the centromere. Lin et al. (1976) described a similar marker as a 'reallocation of a variable band between the area of p11 and q11 of chromosome 3' and did not consider it a structural chromosome aberration. The Paris Conference (1971) listed the centric region of chromosome 3 as 'variable' by Q-banding. Similar definitions were not outlined for C-banding at the Paris Conference, but variants, particularly of the secondary constrictions and some darkly staining areas in non-centromeric regions, are well known (Craig-Holmes et al., 1973; Carnevale et al., 1976).

To the best of our knowledge the $\mathrm{C}$-band in chromosome 11 has not been reported as located elsewhere than at the centromere itself. McKenzie and Lubs (1975) classified the C-band of chromosome 11 as the second largest in group C. In a survey of 376 neonates Müller et al. (1975) found large C-band variants in $13 \%$ of chromosome $11 \mathrm{~s}$.

It might perhaps be argued that an abnormal location of a band within a variant region is not an inversion unless there is evidence of meiotic crossing over within the inverted segment, yielding unbalanced recombinants in the offspring. But if this were so, several clear-cut human inversions would not meet the criteria ( $c f$. Moorhead, 1976).

We, therefore, tentatively define the abnormal chromosome as a pericentric inv(11)(p11q11) because it is not merely a size variant of the C-band. However, we recognise that it may be a matter for discussion whether it should be defined as a location variant instead.

The clinical significance of both inversions described appears to be negligible or at least questionable. This is in line with previous findings for other inversions found in this laboratory (de la Chapelle
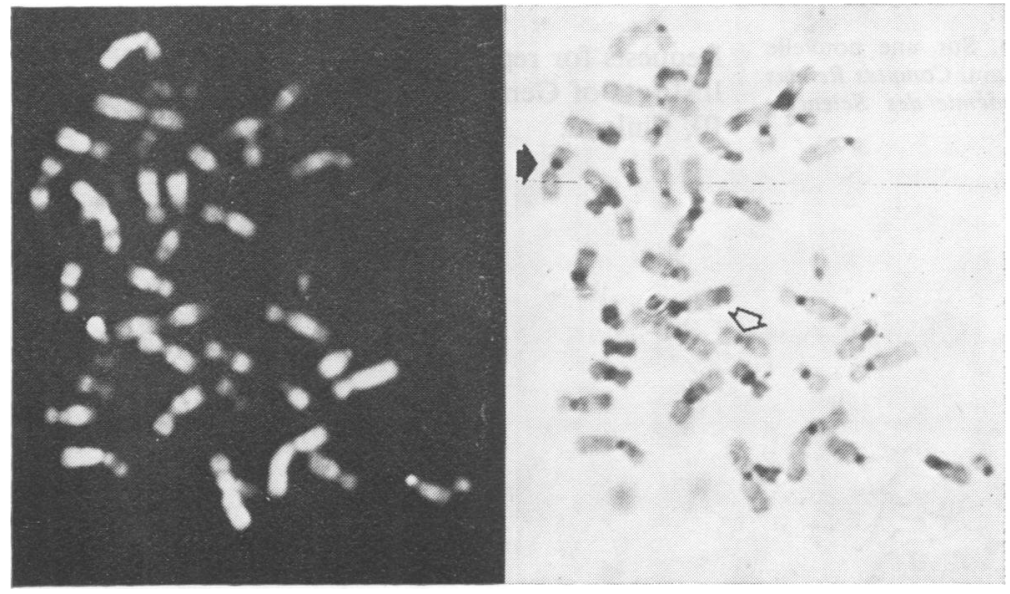

Fig. 4 Partial metaphase stained successively with the $Q$ and $C$-banding methods. The normal chromosome 11 is indicated by an open arrow and the inv(11) (p11q11) chromosome by a closed one. 


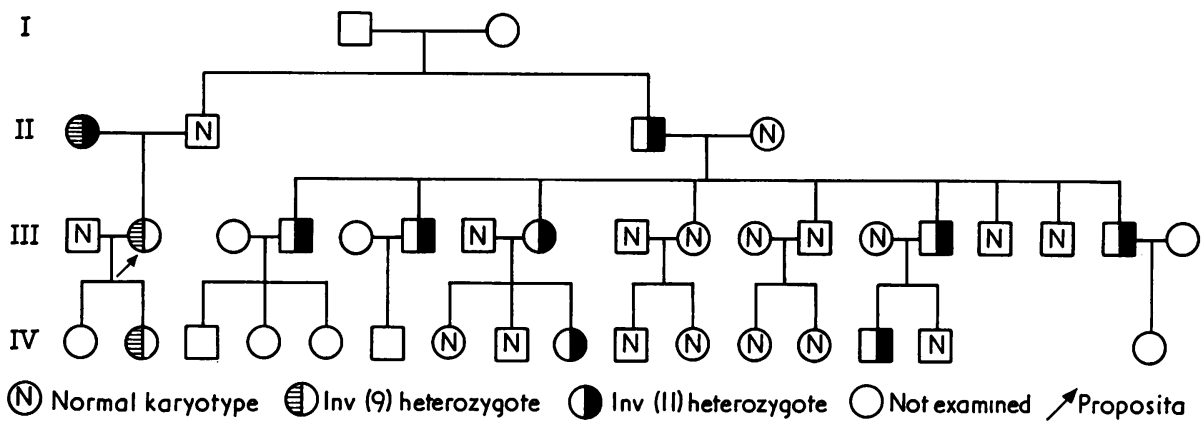

Fig. 5 Pedigree of the inv(11) (p11q11) family.

et al., 1974; Herva and de la Chapelle, 1976) and in several others as well (Moorhead, 1976).

We thank Dr Pertti Aula for information on a pre- and postnatally determined karyotype. This work was supported by grants from the Oskar Öflund Foundation and the Sigrid Jusélius Foundation.

\section{References}

Arrighi, F. E., and Hsu, T. C. (1971). Localization of heterochromatin in human chromosomes. Cytogenetics, 10, 81-86. Carnevale, A., Ibanez, B. B., and del Castillo, V. (1976). The segregation of C-band polymorphisms on chromosomes 1 , 9 and 16. American Journal of Human Genetics, 28, 412-416.

Caspersson, T., Zech, L., Johansson, C., and Modest, E. J. (1970). Identification of human chromosomes by DNAbinding fluorescent agents. Chromosoma 30, 215-227.

de la Chapelle, A., Schröder, J., Stenstrand, K., Fellman, J., Herva, R., Saarni, M., Anttolainen, I., Tallila, I., Tervilä, L., Husa, L., Tallqvist, G., Robson, E. B., Cook, P. J. L., and Sanger, R. (1974). Pericentric inversions of human chromosomes 9 and 10. American Journal of Human Genetics, 26, 746-766.

Craig-Holmes, A. P., Moore, F. B., and Shaw, M. W. (1973). Polymorphism of human C-band heterochromatin. I. Frequency of variants. American Journal of Human Genetics, 25, 181-192.

Dutrillaux, B., and Lejeune, J. (1971). Sur une nouvelle technique d'analyse du caryotype humain. Comptes Rendus Hebdomadaires des Séances de l'Académie des Sciences, 272, 2638-2640.
Herva, R., and de la Chapelle, A. (1976). A large pericentricr inversion of human chromosome 8. American Journal of Human Genetics, 28, 208-212.

Lin, C. C., Gedeon, M. M., Griffith, P., Smink, W. K. Newton, D. R., Wilkie, L., and Sewell, L. M. (1976)? Chromosome analysis on 930 consecutive newborn children using quinacrine fluorescent banding technique. Humaß Genetics, 31, 315-328.

McKenzie, W. H., and Lubs, H. A. (1975). Human $Q$ and chromosomal variations: distribution and incidence Cytogenetics and Cell Genetics, 15, 97-115.

Moorhead, P. S. (1976). A closer look at chromosoma $\overrightarrow{0}$ inversions. Editorial. American Journal of Human Genetics, 28, 294-296.

Müller, Hj., Klinger, H. P., and Glasser, M. (1975). Chromoo some polymorphism in a human newborn population IIs Potentials of polymorphic chromosome variants for char acterizing the idiogram of an individual. Cytogenetics and Cell Genetics, 15, 239-255.

Paris Conference (1971). Standardization in human cyto@ genetics. Birth Defects: Original Article Series, VIII: $7 \overrightarrow{\bar{S}}$ 1972. The National Foundation, New York.

Pruzanski, W. (1966). Variants of myotonic dystrophy in pre-adolescent life. (The syndrome of myotonic dysembryo plasia.) Brain, 89, 563-568.

Seabright, M. (1971). A rapid banding technique for human chromosomes. Lancet, 2, 971-972.

Soudek, D., O'Shaughnessy, S., Laraya, P., and McCreary? B. D. (1974). Pericentric inversion of 'fluorescent' segment in chromosome No. 3. Humangenetik, 22, 343-346.

Requests for reprints to Dr. K. Simola, Folkhälsan Institute of Genetics, P.O. Box 819, 00101 Helsink 10, Finland. 